\title{
Planet Greening
}

\author{
Oleg Khalidullin* \\ Kazakh National University, Kazakhstan \\ *Corresponding Author: Oleg Khalidullin, Kazakh National University, \\ Kazakhstan.
}

DOI: 10.31080/ASMI.2020.03.0529

And on Mars apple trees will bloom. Words from a song Climate change has become a proven fact. Long droughts lead to fires. So the forests of America, Siberia, the Amazon burn. On the contrary, deserts, in which there is usually no moisture, receive enhanced portions of rainfall, in the form of rain, snowfall, which negatively affects the desert biota. Glaciers are melting, the level of the oceans is rising.

Deserts are approaching semi-deserts, semi-deserts on the steppes and shrouds, quarries for mining and non-useful minerals, mine dumps and landfills are growing, rivers are becoming shallow. The area of forests is steadily decreasing - in ten years it decreased by 1.4 million $\mathrm{km} 2$ - [1], erosion of abandoned virgin and fallow lands - up to 1.5 million ha annually becomes worthless: [2]. To this should be added direct seizures of fertile land for the construction of cities, roads, airfields. All of humanity ruined $70 \%$ of the inhabited land. Water falling on damaged lands does not find its original consumer and returns to heaven without performing its natural functions. These are artificial fumes that change the basis of the hydrological cycle.

- $\quad$ Raised vapors from destroyed areas have a different quality - the evaporation from an animal's respiration or from a green leaf cannot be the same as from water from a puddle on asphalt or from arable land.

- $\quad$ The volumes of artificial fumes began to approach or even exceed the volumes of organic fumes.

- $\quad$ The rate of evaporation can be judged from mental experience. How long does it take to evaporate a bucket of water poured onto asphalt and from water poured onto a green meadow. Water from asphalt will evaporate in a few minutes, and under a meadow of untouched soil, 20 tons of underground living creatures on each hectare await. Moisture, transformed by many organisms, goes back into the atmosphere by breathing vapor, excretion in a week, a month.
Received: January 07, 2020

Published: February 19, 2020

(C) All rights are reserved by Oleg Khalidullin.
Here are three factors that control the water cycle. The changed hydrological cycle affects the climate and warns us of a general cataclysm by the growth of natural disasters.

If we want to preserve the habitability of the planet for our descendants, it is urgent to return to nature the most important link in a single chain of the water cycle - to increase organic evaporation and reduce artificial evaporation. More details can be found here: [3].

For this, nature needs to return its natural soils and forests. One of the many, but significant problems of nature restoration is the restoration of ruined lands.

Existing methods of forest planting are based on digging trenches and inserting seedlings into the holes. The processes are laborious and inefficient, provide for manual labor. All underground living creatures around the hole and in the trench are destroyed. The speed of planting and growing a tree is dozens of years.

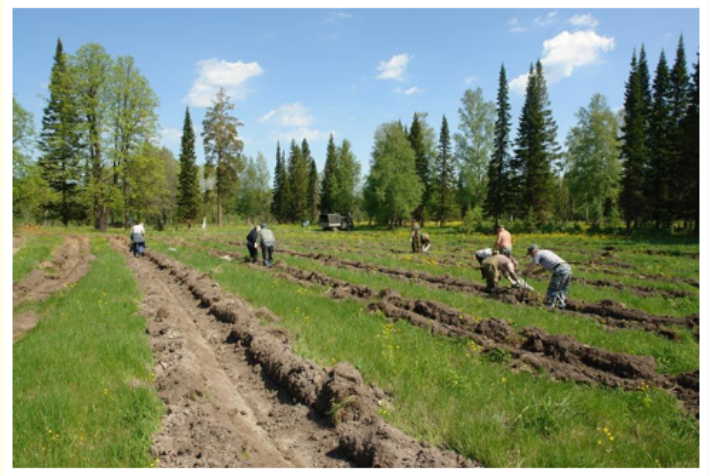

Figure 1 
Reforestation is far behind the rate of deforestation. Modern logging technologies are similar to mowers in productivity. In a few seconds, a special machine turns a tree into a stack of logs.

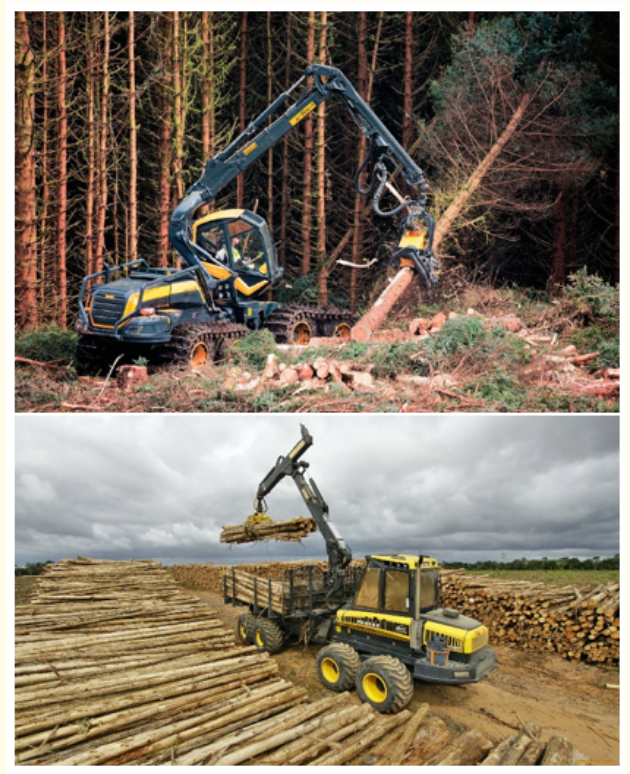

Figure 2

Tree planting in volume and afforestation should be equal in balance. After compensation for the cut down forest earlier. Known manual and mechanized landings do not match this landing speed. A cardinal massive landscaping of the destroyed territories is necessary.

An interesting step towards this was taken in Russia - planting from small aircraft - [4]: "The Tatarstan Small Aviation Center intends to test in the Ulyanovsk Region a new technology for planting conifers with seedlings using aircraft, which, according to the authors of the project, should be several times cheaper than traditional land landing" (Figure 3).

[5]: "The method consists in landing material being dropped from aircraft at an altitude of 100-250 meters to unprepared soil. In this way, you can plant not only planting material with a closed root system, but also cuttings of trees, as well as sprouted seeds in special capsules along with the necessary trace elements and soil. " The process is so laborious that it was not possible to repeat and develop it in the future. And the surrounding competitive grass stand did not give growth opportunities.

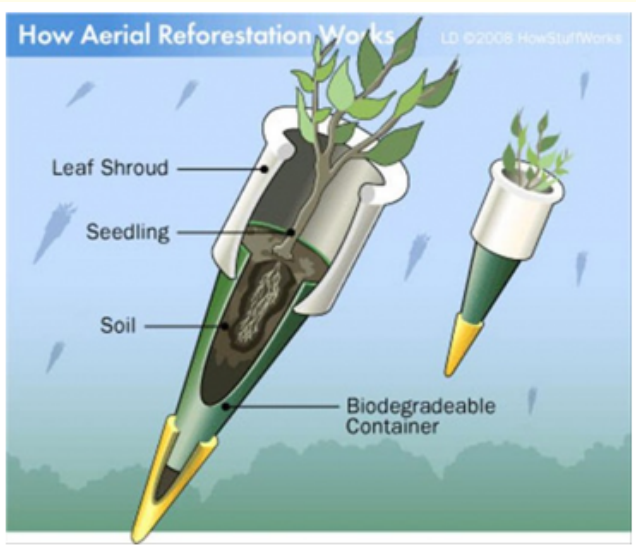

Figure 3

The experiment [6] was more successful: "During the times of the USSR Ministry of Forestry (1947 - 1953), coniferous aerial sowing was carried out on concentrated cuttings of the European North and saxaul airborne sowing in the semi-deserts of Central Asia. The survival rate of such seedlings is $93 \%$, which is 3-4 times higher than the survival rate of ordinary seedlings and seeds. This is an effective technology, which is now in great demand."

However, the main advantage of the pilot project is not so much in the seedlings as in the method of planting them, namely, using airplanes, the company explains. The technology's efficiency is at least ten times higher than the "manual" planting method due to high productivity and about half reduction in the cost of reforestation."

[7]: "According to the conclusions of experts, the technology needs refinement, because due to the small weight of the structure, the seedlings are not stuck deep enough into the ground. In addition, the area allocated for air landing, do the land should be at least 50 ha. " Other scales are needed, the degree of improvement of preparedness of planting areas and a large penetration force into the soil.

The authors of [8] approached such a technical solution: "Forests on the Planet can be restored very quickly, with the help of outdated bombers designed to install minefields. All that is needed is to convert them into seed bombs containing tree seedlings." 
This innovation has a great prospect, to plant all the destroyed places of the planet with forest, shrubs and grasses. However, mastering aging equipment, maintaining airfields, requires a considerable staff of qualified specialists. Create a new industry. It is difficult to solve problems associated with temporary factors and efficiency. Wet soil can be very short 1 - 2 days, maybe a week in a year, with non-rising local vegetation. Guessing and using such conditions is not so simple.

But what if we use civilian airliners and cargo planes. In fact, all planes, burning fuel, destroy air moisture. During take-off and landing in the surface zone and up to a height of 5 kilometers, the air humidity is quite high and contains up to $10 \%$ moisture. Above $10 \mathrm{~km}$, the moisture content has a small percentage, but with a long flight, this moisture is also destroyed. All engines drive through themselves and burn giant masses of water molecules, turning them into artificial fumes. Therefore, aircraft technology is simply obliged to compensate for the damage that the atmosphere causes in the air and the destruction of the areas under the runways.

50,000 of these planes daily fly in the air around the world. Flight schedules are scheduled months in advance.

It is known that civilian aircraft often fly with partial load. An empty seat in flight is $50-90 \mathrm{~kg}$ of shortfall of the nominal load, plus its luggage of $20 \mathrm{~kg}$. And if the seats are free for 5-50 people? Adding another mechanism for seed ejection somewhere in the tail section to a thousand different airliner devices will not be very difficult. There are similar devices for dropping bombs, ejecting pilots, water to extinguish fires, others - such as refueling in the air. Cargo planes can carry even more seeds or seedlings when returned empty. At a given time, all or part of these seeds are discharged at a given location. The time and dispersion zone is calculated in advance for each location. There is such experience in extinguishing forest fires. And the accumulated experience of spot planting can lead to sowing seeds in ordinary fields. Seeds and seedlings are granulated with a sufficient amount of moisture and nutrients in balls or in cones with tops below. When flying over a deserted, degraded place, over arable land, millions of these granules dig into moist, better wet soil. Such soil can be in autumn, spring, after snowmelt and heavy rain. Part of the seeds can germinate and create a new habitat. When planting seedlings in the steppe zone, the moment of planting should be immediately after snowmelt, in late autumn or early spring, when the local grass stand has not yet wo- ken up. These points are determined by local agronomy services. Thus, a possible simple technological process creates a revolutionary technology for mass gardening of the lost surface of the Earth. Perhaps planned planting in the fields.

It will also be possible to dump the embryos of the necessary insects, small animals in special containers after creating a new green cover.

Seeds and seedlings can be granulated in a fairly durable shell, from nutrients. Such machines and production complexes for granulating seeds exist and are produced - [9].

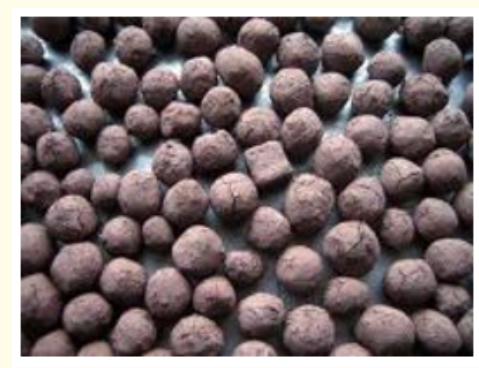

Figure 4

Naturally, it will require a variety of calculations, the design of mechanisms. The most difficult will be the organizational arrangements. But the goal is to stop soil erosion, return to nature its flora and fauna can stop climate change. It seems possible to sow large areas with seeds and seedlings of vast steppes and deserts with their forest sowing material. Then deserts and ore dumps will turn into steppes, and steppes and shrouds into forests.

Daily flights of aircraft with their trajectories cover almost the entire surface of the Earth. If necessary, there may be minor route adjustments. With such an organizational capacity of airports, which we observe during check-in, landings, customs control, and preparing the aircraft for the flight. The additional load among hundreds of others, in the form of seed loading will even be invisible. of course, there will be a separate service for agronomists, new specialists, suppliers and seed processors, loaders. The agronomic service will have to have specialists who can, depending on winds and precipitation, in a given area, recommend when, how much and in what places to make seed emissions. 
No less important may be the use of a new device for processing forests and steppes from pests, example, locust chemicals and other pests.

\section{Conclusion}

Thus, the use of the existing civil aviation aircraft flight system will create an unprecedented, in terms of productivity, technology for planting degraded areas, improving the landscaping of all territories. The main effect will be a significant reduction in anthropogenic impact on the climate and a contribution to the possibility of saving life itself on the planet.

\section{Bibliography}

1. https://en.wikipedia.org/wiki/\%D0\%9E\%D0\%B1\%D0\% B5\%D0\%B7\%D0\%BB\%D0\%B5\%D1\%81\%D0\%B5\%D0\% $\mathrm{BD} \% \mathrm{D} 0 \% \mathrm{~B} 8 \% \mathrm{D} 0 \% \mathrm{~B} 5$.

2. http://www.zaiko-mich.narod.ru/index.files/page0003.htm

3. https://www.actascientific.com/ASMI/pdf/ASMISI-01-0009.pdf

4. https://www.kommersant.ru/amp/2461878

5. http://ecodorogi.ru/news/867.html

6. http://www.forestforum.ru/viewtopic.php?t=16422

7. https://lesvesti.ru/news/news/7583/

8. http://forums.airbase.ru/2018/12/t91069--bombardirovschiki-mogut-vysazhivat-do-900-000-derevev-v-den.8602. html:

9. http://vitusltd.ru/blog/agriculture/1161l

\section{Assets from publication with us}

- Prompt Acknowledgement after receiving the article

- Thorough Double blinded peer review

- Rapid Publication

- Issue of Publication Certificate

- High visibility of your Published work

Website: https://www.actascientific.com/

Submit Article: https://www.actascientific.com/submission.php Email us: editor@actascientific.com

Contact us: +919182824667 